\title{
Research in Humanitarian Supply Chain Management and a New Framework
}

\author{
Degan YU ${ }^{*}$, Mehmet G. YALCIN ${ }^{* *}$, Koray OZPOLAT $^{* * *}$, Douglas N. HALES $^{* * * *}$
}

\begin{abstract}
With the frequency and magnitude of disasters on the rise, millions of people suffer huge losses every year. Scholars have recently proposed various frameworks in disaster relief management in order to guide the research in this field. Although successful disaster relief requires the entire humanitarian supply chain to respond in harmony, it is surprising that there exists no humanitarian relief framework drawn from the perspective of supply chain management. In this article, we create a new research framework for Humanitarian Supply Chain Management (HSCM) that is complimentary but distinct from commercial supply chain management (CSCM) frameworks. The framework we developed offers a new lens for humanitarian researchers. We also conduct a systematic literature review in this field and identify some opportunities for future research. The results strongly suggest the need for additional empirical research to test the existing concepts and models. Second, there is evidence that research focusing on "upstream" relief chain has been neglected relative to "downstream". Additionally, due to its rapid advancement, information technology related research opportunities in this field would always be there.
\end{abstract}

Keywords: Humanitarian Supply Chain Management, Humanitarian Logistics, Research Framework, Disaster Relief Management, Literature Survey

JEL Code Classification: L310

UDC: 164:339.726.

\footnotetext{
*Ph.D. Candidate in Supply Chain Management, College of Business Administration, University of Rhode Island, USA. E-mail:degan_yu@my.uri.edu

${ }^{* *}$ Ph.D. Candidate in Supply Chain Management, College of Business Administration, University of Rhode Island, USA. E-mail:mgyalcin@my.uri.edu

${ }^{* * *}$ Corresponding Author.Assistant Professor of Supply Chain Management, College of Business Administration, University of Rhode Island, USA. E-mail: koray@uri.edu

${ }_{* * * *}$ Associate Professor of Supply Chain Management, College of Business Administration, University of Rhode Island, USA. E-mail: dhales@uri.edu
} 


\section{Introduction}

Disasters occur worldwide each year. According to the statistics data ${ }^{1}$ from The United Nations Office for Disaster Risk Reduction (UNISDR), between 2000 and 2012, 1.2 million people were killed and 2.9 billion were affected by different kinds of disasters. The estimated economic impact of the damages totaled approximately USD 1.7 trillion in the same period. These numbers suggest that disaster preparation and relief have huge economic and humanitarian implications. Civil society responded by creating more nongovernmental organizations (NGOs) focusing on disaster preparation and aid. As of 2012, the number of NGOs operating in the United States has reached 1.5 million (Human rights' report, 2012). Academics have also recently addressed the issue from multiple perspectives, including public policy, civil engineering, urban planning and particularly operations and supply chain management. For example, a new dedicated journal - Journal of Humanitarian Logistics and Supply Chain Management - started in 2011 and the number of articles published in a variety of academic outlets has been increasing as well. Despite this positive trend, not all areas in disaster relief receive attention and more application of supply chain management thinking is required in humanitarian operations and disaster relief (Galindo and Batta, 2013). In this study, we develop a new humanitarian supply chain management (HSCM) framework and survey the relevant literature to identify these under-researched areas.

Our exploratory study shows that some systematic literature reviews have been conducted in this emerging field. Specifically, Altay and Green (2006) survey the $\mathrm{OR} / \mathrm{MS}$ literature in disaster relief management area and classify studies by disaster relief phases, research methodology, research contribution, disaster type, and problem scenario to identify publication trends. Galindo and Batta (2013) evaluate how OR/MS research in Disaster Operations Management (DOM) has evolved over the past seven years and to what extent the voids identified by Altay and Green (2006) have been filled; they find that there are no striking changes or developments in this field. Natarajarathinam et al. (2009) are the first to provide a literature review on supply chain crisis management, a different concept than traditional risk management. By reviewing and analyzing the literature prior to August 2008, they describe the current practices, research trends and future research direction in supply chain crisis management area.

Two other articles, Kovacs and Spens (2007) and Overstreet et al. (2011), propose frameworks to guide this relatively new research area. Kovacs and Spens' (2007) framework addresses disaster relief logistics differentiating between actors, phases, and logistical processes of disaster relief. Their framework distinguishes the phases of humanitarian relief chain management and types of operations but does not offer a landscape from the viewpoint of supply chains. Overstreet et al. (2011) use the theory of constraints and the management information systems literature

\footnotetext{
${ }^{1}$ Source: http://www.preventionweb.net/files/31737_20130312disaster20002012copy.pdf
} 
to develop a research framework using elements of logistics, which include organization's personnel, infrastructure, planning/policies/procedures, transportation, information technology, and inventory management. While the proposed "input-output" system model includes different elements of humanitarian logistics, it does not depict the "flow-through" feature of supply chains. Likewise, some other frameworks are drawn from perspectives of either disaster phases (e.g., Maon et al., 2009) or part of supply chain system (e.g., Ertem et al., 2010). To the best of our knowledge, there exists no framework for this field that emphasizes "flow-through". This observation raises a question: Can we develop a research framework that emphasizes "flow-through" feature for humanitarian supply chains by borrowing from existing commercial supply chain frameworks?

To address the above question, in this article we create a new framework for humanitarian supply chains that is complimentary to, but distinct from the framework of commercial supply chains. We initially shaped our framework by borrowing from an existing CSCM framework of Mentzer et al. (2001) and revised our framework along with the process of our systematic literature review. We then identify some opportunities for future research in this area after a systematic literature review. The following figure (Figure 1) demonstrates our research process.

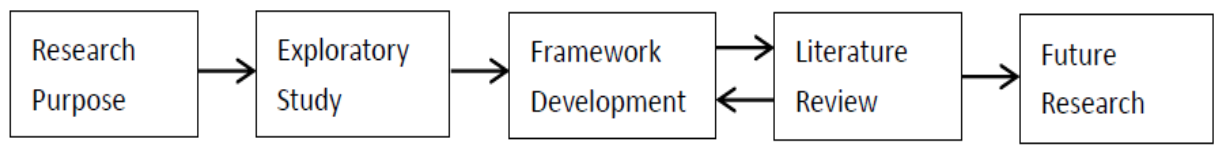

Figure 1. Research Process

In the next section we briefly introduce humanitarian supply chains. Section 3 examines existing frameworks of commercial supply chain management (CSCM) that match the characteristics of humanitarian supply chain management (HSCM) from which a new framework for HSCM is developed. Then, we collect extant articles and categorize them according to our framework in section 4. The surveyed literature is analyzed using the newly developed framework and we conclude by providing future research directions.

\section{HSCM in Context}

HSCM is referred to as the process of effective and cost-efficient plans, implementations and controls for aid flows (i.e., materials, goods, services, financial resources, information, etc.) from the point of origin to the point of consumption with the intention of meeting the aid recipients' requirements (Thomas and Mizushima, 2005; Day et al., 2012; etc.). As a subset of supply chain management, it covers almost all of the functional processes that a CSCM does, including processes such as sourcing, procurement, inventory management, logistics and distribution, information management, and so forth (Day et al., 2012). 
However, unlike the "financial" objectives of CSCM, the primary goal for HSCM is to minimize human suffering -- more specifically to prevent further loss of life and harm to humans, as well as provide immediate treatment to those with injuries and illness (Beamon and Balcik, 2008).

On the other hand, as have been discussed by some researchers, humanitarian supply chains operate under highly uncertain conditions relative to commercial supply chains (e.g., Wassenhove, 2006). First of all, the unpredictability of disaster occurrence and the magnitude of damage make forecasting extremely difficult. Second, the typical collapse of infrastructure in the affected area severely inhibits aid to the disaster region. Third, the humanitarian supply chain network is temporary making the management of the whole system especially challenging. Meanwhile, raising the necessary financial and material resources is difficult to predict because each disaster is unique. These factors collectively shape humanitarian supply chain as a complex and delicate system, thereby making the management of humanitarian supply chains more challenging compared to CSCM.

These unique characteristics of humanitarian supply chains require a high level of agility, flexibility and effectiveness (e.g., Holguin-Veras et al., 2012). Since saving lives and reducing human suffering are top priorities during disaster, the management philosophies accordingly differ from those of CSCM. For example, distinct from the traditional cost minimization and profit maximization objectives for CSCM -- the objective of HSCM is minimizing social costs, which is comprised of both supply chain costs and deprivation costs (Holguin-Veras et al., 2012).

Researchers often rely on frameworks to analyze such complex phenomena, which motivates us to provide in-depth discussion in the next section.

\section{Developing a Framework for HSCM}

\subsection{Existing Frameworks for CSCM}

Good research frameworks help people make logical sense of the relationships of the variables and factors that are relevant or important within the scope of a research arena. Over the past decades, a number of scholars (e.g., Bowersox, 1996; Chen and Paulraj, 2004; Lambert et al., 1998; Mentzer et al., 2001; etc.) have proposed frameworks for CSCM, each focusing on some aspects of supply chains. In the following, we briefly discuss several existing CSCM frameworks and explain our criteria of selecting framework for groundwork as our framework development. For instance, Lambert et al. (1998) proposed a three-part framework for CSCM which integrates business processes, potential structures of supply chain and key components for supply chain management with limited flow characteristics (see Figure 2).

Chen and Paulraj's (2004) model, as another example, emphasizes the features of interdependent and collaborative relationships within a supply chain network (see Figure 3). Their framework greatly depicts the intricacies of the "network" system. 


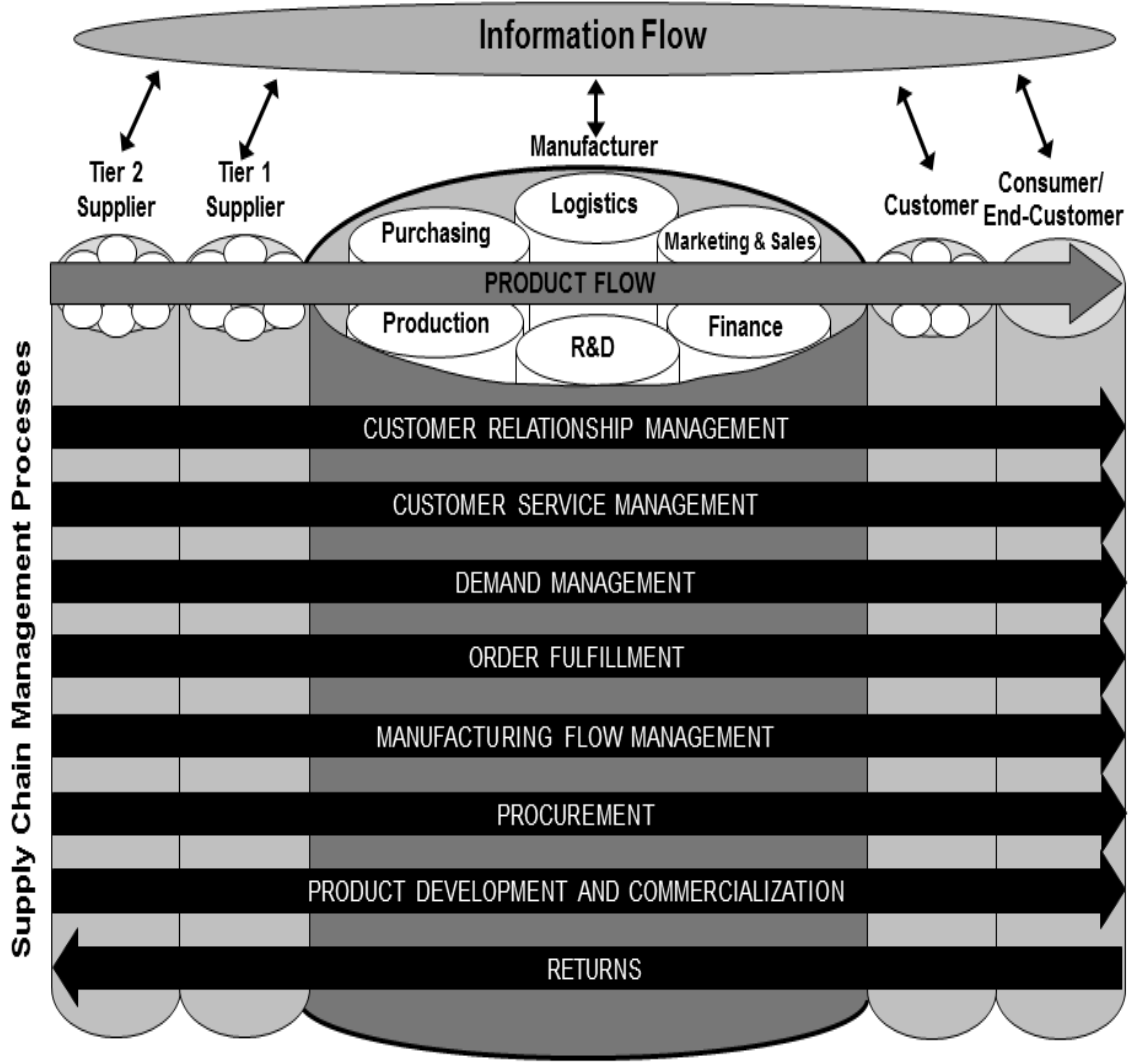

Figure 2. Lambert et al. (1998) supply chain framework

We notice that the flow property of supply chain is not emphasized in frameworks such as those we listed above. One SCM framework, proposed by Mentzer et al. (2001) emphasizes the supply chain flows on the amplified interface between the focal firm and its outside business environment.

In specific, their framework covers aspects of system players, business functions, coordination, supply chain flows, SCM goals, etc. (see Figure 4). This framework puts a focal organization at the center of the entire system of supply chains. The related business functions support different business processes operated by the company. To achieve its business goal(s), the focal company as an organic entity requires internal coordination to integrate all business functions. Moreover, the focal company needs to deal with various stakeholders such as suppliers, customers, third-party providers, etc. For the purpose of this research, after reviewing the existing frameworks, we chose Mentzer et al.'s (2001) as a foundation because through explicitly depicting each variable/component, their framework fits well with the unique traits of humanitarian supply chains and our intention of emphasizing "flow-through" trait. 


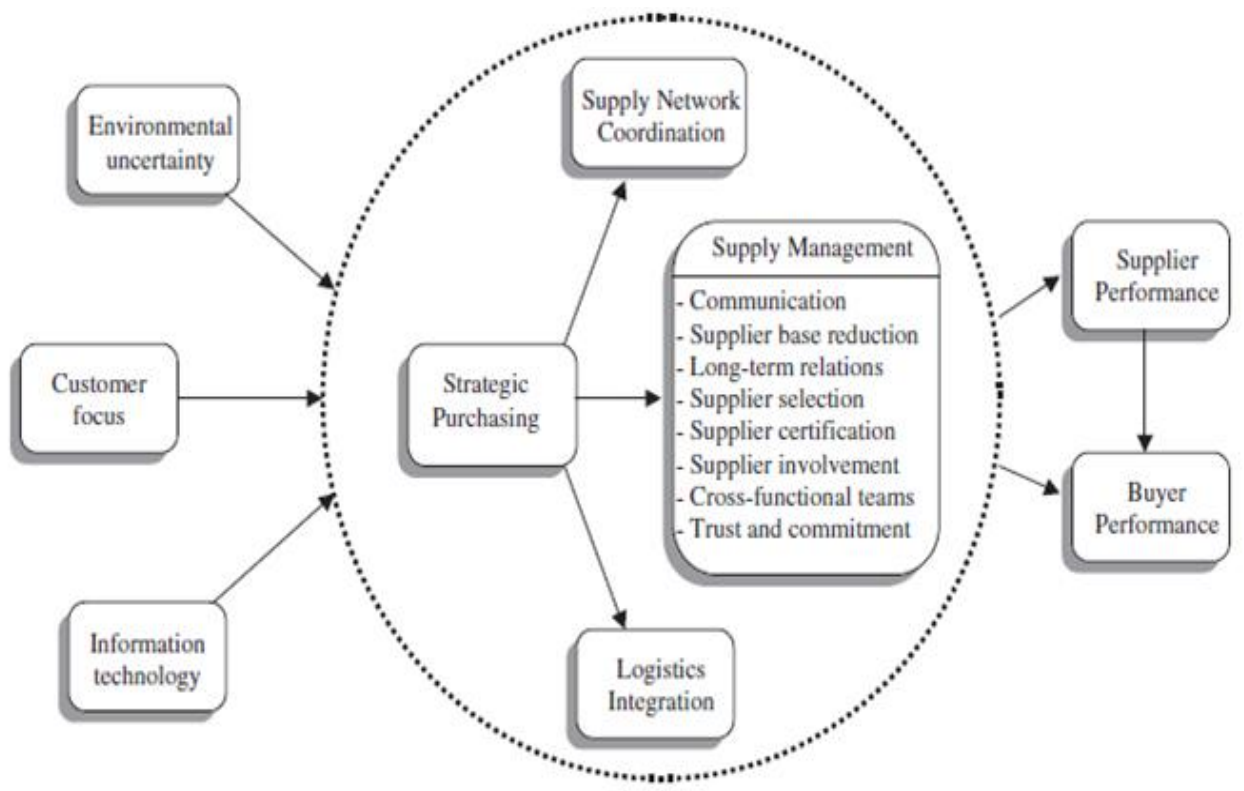

Figure 3. Chen and Paulraj (2004) supply chain framework

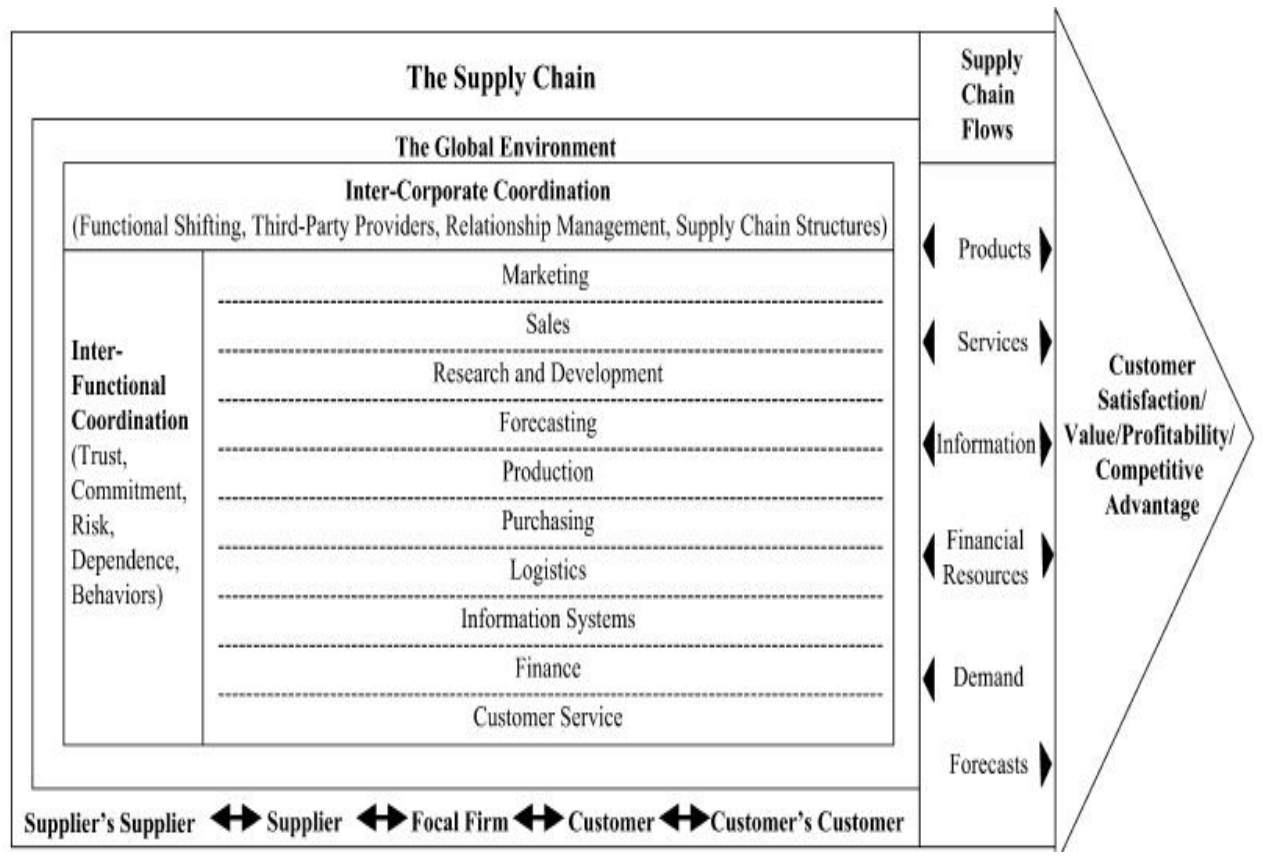

Figure 4. Mentzer et al. (2001) Framework of Supply Chain Management 


\subsection{A New Framework for HSCM}

Supply chain management is a concept, "whose primary objective is to integrate and manage the sourcing, flow, and control of materials using a total systems perspective across multiple functions and multiple tiers of suppliers" (Monczka et al., 1998). Using the paradigms of existing frameworks for CSCM and borrowing from the framework proposed by Mentzer et al. (2001), we develop a framework for HSCM with an intention to capture characteristics of both disaster relief management and humanitarian development aid management.

Humanitarian Aid Organization: At its epicenter, our framework (Figure 5) positions the individual humanitarian aid organization which aims to reduce the human suffering in the affected areas. The other components of our framework further extend to upstream and downstream of the focal individual humanitarian aid organization and altogether weave the humanitarian supply chain structure.

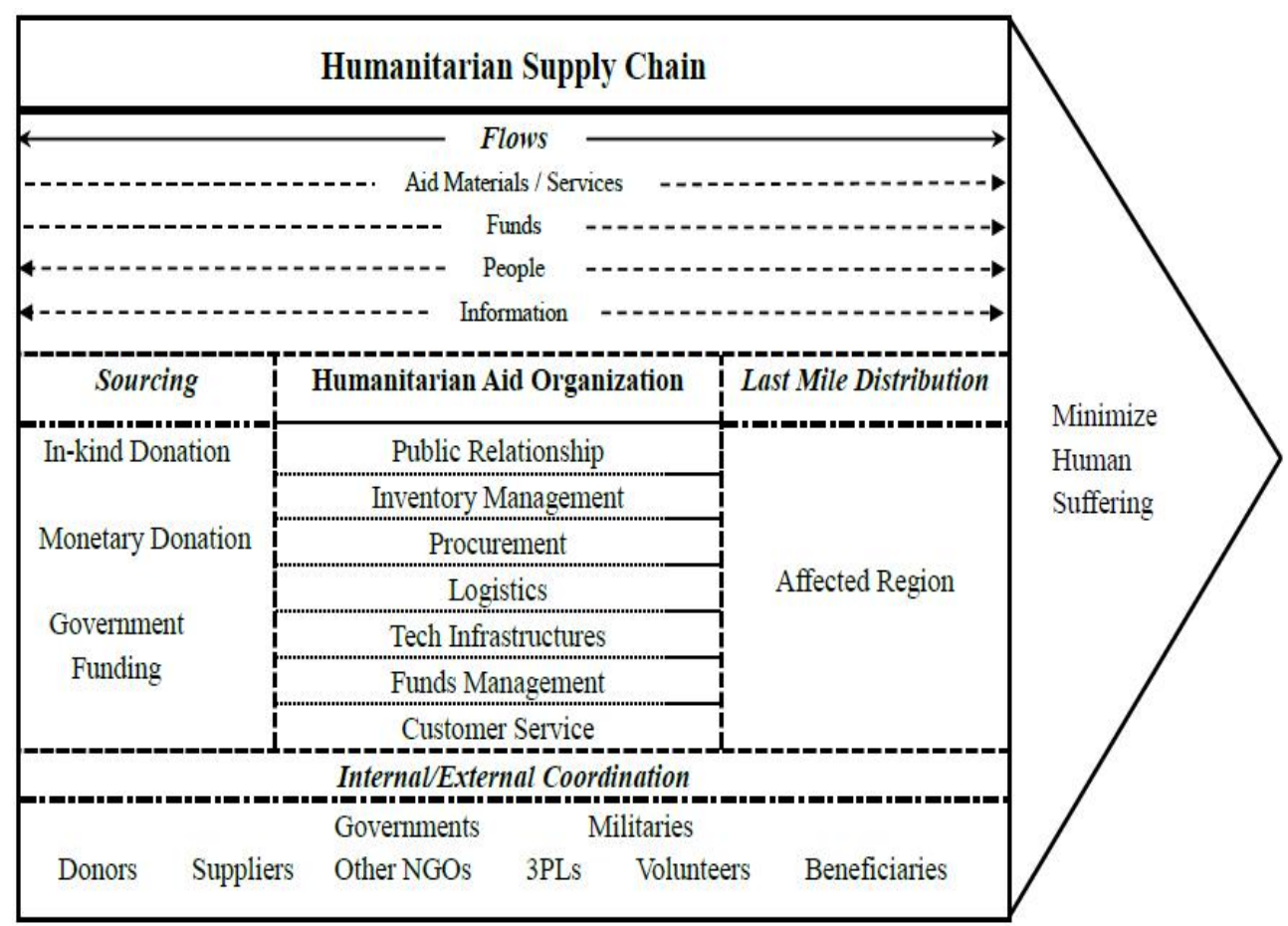

Figure 5. A New Framework for HSCM

Although "humanitarian aid organization" is a more general term, typically NGOs act as main players in humanitarian aid management when a disaster occurs. It is worth mentioning that humanitarian aid organizations involving in humanitarian aid activities include humanitarian agencies (HAs), NGOs, disaster relief organizations, and humanitarian organizations (HOs), etc., and there are some 
differences among the definitions of these organizations (Therien and Lloyd, 2000). For the purpose of this study, we treat "NGO" and "humanitarian aid organization" as interchangeable in our framework ${ }^{2}$. Other framework components include sourcing, internal and external coordination, flows and last mile distribution.

Sourcing: For NGO operations, source is of particular importance given their dependence on resource injection ${ }^{3}$. The source consists of either monetary or nonmonetary resource. In other words, source from outside is imperative to an NGO's operations. According to Beamon and Balcik (2008), NGOs' source of revenue mainly comes from governmental funding in addition to charitable and inkind donations, which refer to nonmonetary contributions such as goods and commodities. In our framework, we categorize sources that segregate the input of an NGO's supply chain system into three types, including "in-kind donation", "monetary donation" and "government funding". This is reflected in the external coordination activities usually conducted by an NGO's functional teams of public relationship, source raising, etc. In fact, due to the significant role of donors, most NGOs currently regard donors as their customers as well (Beamon and Balcik, 2008). Hence the design and management of humanitarian supply chains emphasize donors' heterogeneous goals.

Internal/External Coordination: Further, the coordination within an NGO and outside with the other stakeholders is deemed pivotal for the success of humanitarian aid operations. On the sourcing end, the coordination between an NGO and its donors can be demanding due to the importance of donations to an NGO's operations as well as the heterogeneity of goals from different groups of donors. At the same time, within a humanitarian supply chain, the coordination between an NGO and other players (e.g., other NGOs, governments, etc.) is complicated due to the unique characteristics of this system. For instance, when a major disaster happens, usually there are thousands of disaster relief organizations participating in the relief activities. This would make the coordination far too complex. For instance, the number of NGOs operating in Haiti after the 2010 earthquake was estimated to be between 3,000 and 10,000; the $\mathrm{OCHA}{ }^{4}$ directory of registered NGOs and their key contacts is 82 pages long (Tatham and Pettit, 2010). In addition, the coordination within humanitarian supply chain is extended to other fields such as governments, militaries, other NGOs, etc., as shown in Figure 5. All these facts have made the coordination very challenging for any NGO that participated during the earthquake. It is worth mentioning that trust and information are two key success factors for the coordination within this system.

\footnotetext{
${ }^{2}$ We put "humanitarian aid organization" in our framework for the purpose of enabling our model to capture broader concept; while we use "NGO" most of the time when describing our framework to make it easier to understand.

${ }^{3}$ Resource injection refers to the resources that come from external or in-kind funding/donation, etc., rather than production internally. In Accounting/Finance areas, organizations can grow internally and/or externally.

${ }^{4}$ OCHA: United Nations Office for the Coordination of Humanitarian Affairs
} 
Both factors have gained academic researchers' attention and there exist two streams of literatures focusing on trust (e.g., Tatham and Kovacs, 2010) or/and information (e.g., van der Laan et al., 2009).

Flows: In the typical commercial supply chain framework, three types of flows occur (i.e., materials or goods/services, information, and finance). This is also the case within humanitarian supply chain. In Mentzer et al.'s (2001) framework, the information flow is bi-directional while the financial flows occur from the customer to the upstream suppliers, and the goods flow from upstream down to customers. In our framework, the aid elements (e.g., goods/services and funds) are constructed as flowing out to affected areas whereas information and people are bi-directional. The component of "sourcing" which we purposely emphasize generates the unidirectional input flows for the humanitarian supply chain system. Similar to commercial supply chains, bi-directional information flow is necessary for humanitarian supply chains. It is worth mentioning that "people" is one of the crucial aid flow elements in NGOs' humanitarian operations management. When a disaster takes place, the NGOs' field staff near the affected region would always involve in the aid activities; also, sometimes NGOs' personnel from other areas (including head office) as well as volunteers are sent to the affected area; while on the other hand, some people in the affected area would be shipped out from the affected region. Most of the volunteers (or other relief activity participants) will step away from the affected region sooner or later.

Access and Last Mile Distribution: Last but not least, distribution management is another essential part for humanitarian aid management. Distributions take place through the entire system and distribution management features aspects ranging from demand management to logistics. However, the affected area becomes the focus of the whole system as soon as a disaster strikes. An NGO involved in the aid activities must forecast the demand from the disaster region; it then needs to expeditiously decide the quantity of resources needed (aid materials, funds, and people) and how to quickly make delivery. To augment the efficiency and effectiveness of distribution, the NGO is supposed to coordinate with the related stakeholders, including third party logistics providers (3PLs), suppliers, governments, militaries, volunteers, donors, aid recipients, other NGOs, among others ${ }^{5}$. The humanitarian aid delivery, especially the last mile distribution, during emergent disaster period has been deemed far more challenging compared to the delivery in commercial supply chains due to factors such as the unreliability of the transportation system in the disaster zone (e.g., Beamon and Balcik, 2008). In our framework, we emphasize "last mile distribution" as an important component.

To summarize, our framework provides a landscape of humanitarian aid operations (typically NGOs) from the perspective of supply chain management. Within this

\footnotetext{
5 "Other players" refer to any other players within humanitarian supply chain system such as local commercial organizations, etc.
} 
framework, a focal humanitarian aid organization, structured by necessary functional departments, operates as one of the agencies of the entire system by delivering aid elements from in-kind donations, funding, and voluntary aids to affected areas in order to achieve the objective of reducing human suffering. As per the framework depiction, the flow-through feature of humanitarian supply chain from upstream to downstream is clearly captured; meanwhile, the framework interlinks the focal humanitarian aid organization to other related stakeholders through the activities of coordination.

Having developed a new research framework for HSCM, next we survey the existing literature and identify areas that need further attention based on our framework.

\section{Article Collection and Categorization}

A systematic literature review was conducted in order to identify opportunities for future research in this area. We performed a literature search on keywords used in the papers in this area, including "humanitarian" or "disaster" or "catastrophe" or "emergency" or "relief" or "crisis" AND "logistics" or "supply chain". All of the nonpublished or non-academic articles from the search results through June 22, 2014 are excluded. Additionally, we reviewed the reference lists and searched from Google Scholar. Based upon our framework we classified the collected articles into nine categories including sourcing, internal coordination, external coordination, aid chain flows, distribution, information, framework, model, and others (see Figure 6).

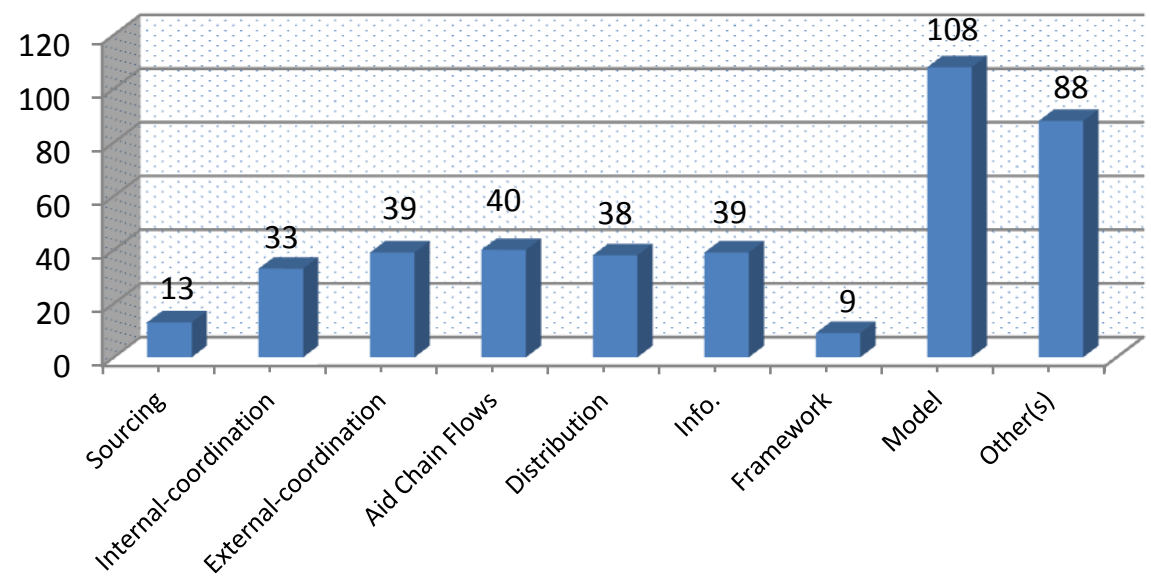

Figure 6. Article Count by Category

We reviewed 293 articles published in 125 academic journals (see Appendix A). Note that 139 articles in this area were published in thirteen out of 125 journals, which account for about $47 \%$ of the total number of our article pool (see Table 1 ). 


\section{Table 1. Journal Ranking by Article Count}

\begin{tabular}{lll} 
No. & Journal & Paper \# \\
\hline 1 & Journal of Humanitarian Logistics and Supply Chain Management & 33 \\
2 & European Journal of Operational Research & 18 \\
3 & International Journal of Physical Distribution \& Logistics Management & 17 \\
4 & Disaster Prevention and Management & 16 \\
5 & OR Spectrum & 9 \\
6 & International Journal of Production Economics & 8 \\
7 & Socio-Economic Planning Sciences & 6 \\
7 & Transportation Research & 6 \\
7 & Disasters & 6 \\
9 & Computers and Operations Research & 5 \\
9 & Journal of the Operational Research Society & 5 \\
9 & Risk Analysis & 5 \\
9 & Safety Science & 5 \\
\hline & Total & 139
\end{tabular}

Another observation is that publications in this field are sparse prior to 2008, but from 2009 the publication trend is increasing rapidly even though the total amount is still small (see Figure 7). During the period prior to 2013, the year 2011 represented the greatest number of articles; although interestingly, the number of published articles has decreased between 2011 and 2013, from 36 to 25. In 2014, the trend appears to be increasing rapidly again with 53 published as of June. It is very likely that the number of published articles in 2014 will jump to a remarkably higher level at the end of the year.

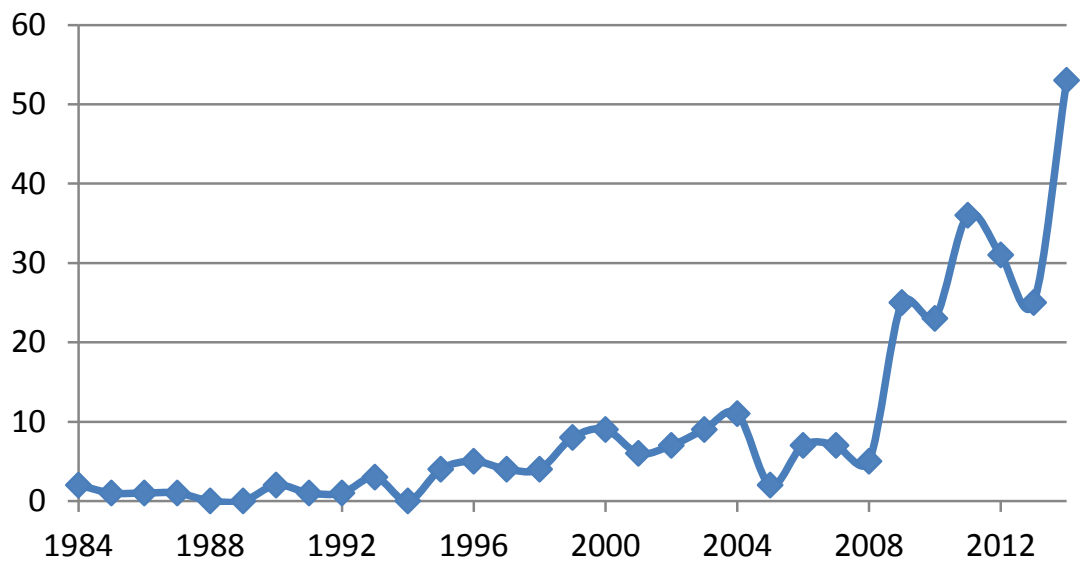

Figure 7. Article Count by Year 


\section{Article Analysis Based on Our Framework}

We performed article analyses in order to further investigate what studies have been done so far. To do this, an approach similar to Galindo and Batta's (2013) is adopted. All the basic information of the articles collected is put together in a form, which consists of variables such as article title, journal name, published year, abstract, article category according to our classification. For each group of the articles, based on our article classification, we went through the abstracts and further looked into the body of the articles to obtain more details if necessary. In this section, we summarize our analyses of the extant literature based on our research framework.

\subsection{Sourcing}

Our analysis result suggests that the extant research on sourcing of HSCM is sparse. In specific, only 13 out of 293 articles focusing on sourcing were published. We also found that most of the existing literature on fundraising is policy-related or consists of work reports. For instance, Özpolat, Ribbink, Hales and Windle (2015) compare two food relief aid strategies: donor country sourcing as commonly practiced by the United States and recipient country sourcing preferred by European Union / United Nations, and provide empirical evidence that both are suboptimal but a flexible sourcing strategy would result in lower total costs. A work report titled "Financing for Humanitarian Operations in the United Nations System", released by Joint Inspection Unit in 2013, also provides a broad discussion ranging from recent trends in global humanitarian financing and financing governance framework to humanitarian financing instruments. However, the academic research on this topic is still rare.

Some scholars pay attention to the proliferation of multilateral donors and attempt to figure out ways to fostering a multilateral donor system that is more efficient and accountable. For example, Reisen (2010) studies the accountability and efficient role assignment in the multilateral donor non-system. The author points out that be it mapping the rising complexity of multilateral development finance, helping identify comparative advantages for an institutional role assignment among multilateral agencies, and helping identify fields for consolidation and address poor coordination and fragmentation across countries - are all crucial to the efficiency of humanitarian aid delivery.

A small stream of literature focuses on the determinants of humanitarian aids. According to these studies, a number of factors have been identified that influence humanitarian aids, such as colonial history, proximity and trade relations, common language, the features of countries (e.g., population, per capita GDP, corruption level, etc.) and disasters (e.g., disaster nature, scale, severity, etc.), the intensity of media coverage, the degree of donors' political and security interest, the strength of humanitarian organizations (e.g., Stromberg, 2007; Selvaretnam et al., 2014; Olsen et al., 2003, etc.). 
There is a debate on the comparative advantages between cash and in-kind donations for disaster aid. Kelaher and Dollery's (2008) case study suggests that cash and in-kind donations are complementary rather than competing methods of delivering assistance. On the other hand, Holguín-Veras et al.'s (2014) study focuses on material convergence that has been neglected by academics. They find that spontaneous flow of supplies, equipment, and general donations to the affected region brings too much needed humanitarian aid materials and major complications for the disaster relief management. The problems created by the non-priority component of the material convergence should receive attention in HSCM.

\subsection{Coordination and Information}

Coordination is especially vital in HSCM due to the complexity of the system. When a disaster happens there are usually a large number of actors involved in the aid activities which make the network of this system extremely complex. Most of the time, no single player has sufficient resources to respond effectively to a severe disaster (Balcik et al., 2010). Moreover, the complexity is added by the heterogeneity of the actors (e.g., different languages and cultures) and the instability of the system. Tatham and Kovacs (2010) describe disaster relief system as a hastily formed network (HFN), which is a rapidly deployable ad hoc network linking humanitarian organizations through inter-sectorial partnerships to other actors such as governments, local communities, business, militaries, etc. In the aftermath of a disaster, the devastated infrastructure (e.g., telecommunication infrastructure) oftentimes aggravates the conditions of coordination.

On the other hand, the increasing need for coordination capabilities within humanitarian supply chain requires support from both information content and information technologies (van der Laan, et al., 2009). Therefore information is playing an increasingly important and more sophisticated role in humanitarianservice activities involving supply chain management. Although information is one type of humanitarian supply chain flows, we combine the analyses of coordination and information given their close tie to each other. Several articles have studied how the related information technologies (or systems) are currently applied in this field. Some researchers (e.g., Baldini et al., 2012; Tomaszewski and MacEachren, 2012; etc.) study the applications/practice of information technologies such as GIS, RFID and customized information systems in this field; while other scholars investigate the management of information or data in humanitarian aid operations. For example, Guven and Ergen (2011) attempt to identify the local information needed by "search and rescue" teams for effective aid responses after an earthquake; while van der Laan, et al. (2009) discuss information cycles management for intra-organizational coordination of humanitarian logistics. There is consensus that improved information enhances the performance of humanitarian supply chains. Given that the advancement of information 
technologies is progressing rapidly, potential research opportunities exist on this topic. We will further discuss this in section 6.

\subsection{Flows and Distribution}

The flows (typically refers to "aid chain flows") in humanitarian supply chain include aid materials, services, people, information, and aid funds. There are a number of articles focusing on different subtopics of aid chain flows. Some investigate the material procurement related issues (e.g., Campbell and Jones, 2011; Chang et al., 2010; Ertem et al., 2012); while others study inventory management and material distribution (e.g., Taskin and Lodree, 2011; Rottkemper et al., 2011).

A study by van Wyk and Yadavalli (2011) proposes a generic mathematical model effectively identifying disaster type and determining the quantities of aid supplies required in prepositioning facilities in the Southern African Development Community (SADC). They also perform a cost-benefit analysis using various budget estimates to illustrate the functionality of their model. Campbell and Jones (2011) ponder decision variables such as delivery speed and risk where they use analytical methodology to model an optimal solution for prepositioning supplies in preparation for a disaster. Pontré et al. (2011) focus on risk assessment and management in humanitarian procurement and supply chain. They examine the procurement risk assessment methodology to provide procurement risk ratings in 60 programs within 26 countries. Although most of the 60 programs are healthcare programs such as HIV/AIDS, Tuberculosis and Malaria, the framework of their study is valuable for similar issues in disaster relief scenarios.

A plethora of analytical articles regarding inventory management or material distribution in this field have been published. For example, Taskin and Lodree (2011) incorporate a prediction model that has been used in a Bayesian decision framework to solve complex decision solutions made in response to an observed tropical cyclone. Their model helps address problems such as determining the appropriate quantities of emergency supplies that should be stockpiled at various locations. Some scholars, e.g., Allahviranloo, Chow and Recker (2014) and Berkoune et al. (2012), analyze routing or transportation problems in distributing relief goods. They propose analytical models to address such problems in accordance with different situations. In short, it appears that inventory management and material distribution has been a hot topic for a while, yet we did not see too many studies, particularly empirical studies, hence we believe more research on this sub topic is needed.

On the other hand, Chang et al. (2010) use both quantitative and qualitative methods to investigate the resourcing issues that concern the provision of resources required for post disaster reconstruction projects and to enable them to be integrated into a holistic planning process. Their empirical result suggests that in order to arrive at a resilient and sustainable built environment after a disaster, 
resourcing efforts should be made around four components, including (1) resourcing facilitator: legislation and policy; (2) resourcing implementer: construction industry; (3) resourcing platform: construction market; and (4) resourcing access: transportation system. In their other article, Chang et al. (2012) determine some difficulties likely to be confronted by the international practitioners in the effort of resourcing for post-disaster reconstruction after comparing the cases between China and Indonesia.

\section{Future Research Directions and Conclusion}

Our review of literature in humanitarian supply chains suggests that more research is still needed in some areas/methodologies although in recent years the research in this arena has gained significant momentum. Based on our article pool, over the past three decades only 293 articles have been published. Although a number of theories or methodologies or techniques from other areas have been successfully used by HSCM scholars, many of these are purely conceptual with 108 (37\%) using analytical research but little empirical examination. This implies that research in this field is still in its stage of infancy, and the need for empirical research to test the concepts and models is strongly evident.

Second, although a large proportion of the existing studies has focused on the "downstream" part of the whole relief chain (e.g., last mile delivery problems), research focusing on "upstream" relief chain has been relatively neglected. The status quo has supported hot topics such as logistics issues in a disaster region, last mile delivery problems, local area coordination during humanitarian relief, and so forth, while studies on fundraising and donation management are sparse. It is understandable since disaster region is the focus of the whole system during disaster relief period. Consequently, researchers would naturally focus on "downstream" part first. However, similar to a commercial supply chain, a humanitarian supply chain is a system that is formed by different components from upstream to downstream; and the whole chain is an "organic" system that requires seamless integration. Hence, the studies on other parts of the whole chain could be a direction for future research. We believe that academic studies on some questions would be very interesting to pursue. To list a few: Does the transparency of an NGO's funds usage audit influence the NGO's source raising ability? How does disaster relief organizations' source raising ability during disaster period influence the performance of humanitarian supply chain? How do different NGOs compete and coordinate on source raisings within the "ecosystem"?

In addition, future research focusing on the component of information within this system could be another direction for research in this area. As previously noted, although there is already a literature stream about information technologies in this field, the IT advancement is progressing so fast nowadays and the research opportunities would always be there. That said, some new information technologies can always be applied in the practice of humanitarian aid activities. 
Researchers can therefore grasp research opportunities, either the new application/implementation of information technologies or emerging management issues arisen from the new application/implementation. For instance, a recent disaster of "missing plane in Asia" has inspired people to think more about using information technologies in humanitarian relief activities. On March 8, 2014 the Kuala Lumpur-Beijing airliner with 239 people on board abruptly disappeared. In the aftermath of this disaster, various governments or organizations from different countries joined the efforts of searching the missing plane. IT technologies such as cloud computing and big data analysis have been used to assist the missing plane search. In particular, big data analysis was adopted for the first time in such activities according to Malaysian Prime Minister NajibRazak's statement ${ }^{6}$. Also interestingly, it is observed that the wisdom and technologies of crowdsourcing have been utilized in the search activities of the missing plane. Additionally, there are some interesting phenomena such as trust and rumors about this event that Operations Management or Supply Chain Management researchers can consider as research topics in humanitarian aid management.

Finally, raising awareness of humanitarian logistics and disaster relief issues through classroom teaching and contests (Özpolat et. al., 2014), simulations (Gralla et al., 2015), and serious games (Özpolat, Rilling, Altay and Chavez, 2015) are other open avenues for researchers.

To conclude, research frameworks are important and necessary because a good research framework draws a big picture of specific area which would be very helpful for people to understand the relationships of the important components and factors within that area. Our exploratory study suggests that most of the existing literature about research frameworks treats the disaster relief management as a logistics system (i.e., "humanitarian logistics"), yet there is a paucity of research frameworks that depict this system from the perspective of supply chain management. This has greatly motivated us to conduct this study. The current article contributes to the extant literature in (1) offering a research framework drawn from a new perspective for disaster relief/aid operations management and (2) taking a snapshot as well as pointing out potential research opportunities in this area. The framework we developed offers a roadmap from a supply chain management perspective for researchers. With this framework we have conducted a systematic literature review and offered directions of potential research opportunities in this field. It has been witnessed that during the development progress of OM/OR academic research, only after people have done effluent research in logistics area did the commercial supply chain begin to receive academics' attention. It appears that history seems to repeat itself. And it is our hope that the framework we propose is helpful for people to see a clearer and more comprehensive picture of humanitarian supply chains and ultimately would guide them in the humanitarian aid operations practice or research in this arena.

\footnotetext{
${ }^{6}$ Source: http://www.bbc.com/news/world-asia-26711298
} 


\section{Acknowledgements}

We would like to thank Professor Paul Mangiameli for his assistance in evaluating our framework; Professor Shaw Chen for his continuous encouragement; and Dr. Nezih Altay, Dr. Yuwen Chen, Dr. Henry Schwarzbach in addition to participants of our presentations for earlier versions of this work at annual conferences of DSI 2014 and NEDSI 2014 as well as URI 2014 Brownbag Seminar for their valuable feedback. We also thank the two anonymous reviewers for their valuable comments and suggestions.

\section{References $^{7}$}

Allahviranloo, M., Chow, J. Y., \& Recker, W. W. (2014). Selective vehicle routing problems under uncertainty without recourse. Transportation Research Part E: Logistics and Transportation Review, 62, 68-88. http://dx.doi.org/10.1016/j.tre.2013.12.004

Altay, N., \& Green III, W. G. (2006). OR/MS research in disaster operations management. European Journal of Operational Research, 175(1), 475-493. http://dx.doi.org/10.1016/j.ejor.2005.05.016

Balcik, B., Beamon, B. M., Krejci, C. C., Muramatsu, K. M., \& Ramirez, M. (2010). Coordination in humanitarian relief chains: Practices, challenges and opportunities. International Journal of Production Economics, 126(1), 22-34. http://dx.doi.org/10.1016/j.ijpe.2009.09.008

Balcik, B., Beamon, B. M., Krejci, C. C., Muramatsu, K. M., \& Ramirez, M. (2010). Coordination in humanitarian relief chains: Practices, challenges and opportunities. International Journal of Production Economics, 126(1), 22-34. http://dx.doi.org/10.1016/j.ijpe.2009.09.008

Baldini, G., Oliveri, F., Braun, M., Seuschek, H., \& Hess, E. (2012). Securing disaster supply chains with cryptography enhanced RFID. Disaster Prevention and Management, 21(1), 5170. http://dx.doi.org/10.1108/09653561211202700

Beamon, B. M., \& Balcik, B. (2008). Performance measurement in humanitarian relief chains. International Journal of Public Sector Management, 21(1), 4-25. http://dx.doi.org/10.1108/09513550810846087

Berkoune, D., Renaud, J., Rekik, M., \& Ruiz, A. (2012). Transportation in disaster response $\begin{array}{llll}\text { operations. Socio-Economic Planning 23-32. } & \text { Sciences, }\end{array}$ http://dx.doi.org/10.1016/j.seps.2011.05.002

Bowersox, D. J., Closs, D. J., \& Helferich, O. K. (1996). Logistical management McGraw-Hill New York. Humanrights' report (2012). "Fact sheet: non-governmental organizations (NGOs) in the United States". Humanrights.gov, Retrieved. http://www.humanrights.gov/fact-sheetnon-governmental-organizations-ngos-in-the-united-states.html

Campbell, A. M., \& Jones, P. C. (2011). Prepositioning supplies in preparation for disasters. European Journal of Operational Research, 209(2), 156-165. http://dx.doi.org/10.1016/j.ejor.2010.08.029

Chang, Y., Wilkinson, S., Potangaroa, R., \& Seville, E. (2012). Resourcing for post-disaster reconstruction: A comparative study of indonesia and china. Disaster Prevention and Management, 21(1), 7-21. http://dx.doi.org/10.1108/09653561211202674

\footnotetext{
${ }^{7}$ For a complete list of articles surveyed, please contact the corresponding author.
} 
Chang, Y., Wilkinson, S., Seville, E., \& Potangaroa, R. (2010). Resourcing for a resilient postdisaster reconstruction environment. International Journal of Disaster Resilience in the Built Environment, 1(1), 65-83. http://dx.doi.org/10.1108/17595901011026481

Chen, I. J., \& Paulraj, A. (2004). Understanding supply chain management: Critical research and a theoretical framework. International Journal of Production Research, 42(1), 131-163. http://dx.doi.org/10.1080/00207540310001602865

Ertem, M. A., Buyurgan, N., \& Pohl, E. A. (2012). Using announcement options in the bid construction phase for disaster relief procurement. Socio-Economic Planning Sciences, 46(4), 306-314. http://dx.doi.org/10.1016/j.seps.2012.03.004

Ertem, M. A., Buyurgan, N., \& Rossetti, M. D. (2010). Multiple-buyer procurement auctions framework for humanitarian supply chain management. International Journal of Physical $\begin{array}{lll}\text { Distribution \& Logistics } \quad \text { 202-227. } & \text { 40(3), }\end{array}$ http://dx.doi.org/10.1108/09600031011035092

Galindo, G., \& Batta, R. (2013). Review of recent developments in OR/MS research in disaster operations management. European Journal of Operational Research, 230(2), 201-211. http://dx.doi.org/10.1016/j.ejor.2013.01.039

Gralla, E., Goentzel, J., \& Chomilier, B. (2015). Case study of a humanitarian logistics simulation exercise and insights for training design. Journal of Humanitarian Logistics and Supply Chain Management, 5(1)

Guven, G., \& Ergen, E. (2011). Identification of local information items needed during search and rescue following an earthquake. Disaster Prevention and Management, 20(5), 458-472. http://dx.doi.org/10.1108/09653561111178916

Holguín-Veras, J., Jaller, M., Van Wassenhove, L. N., Pérez, N., \& Wachtendorf, T. (2012). Material convergence: Important and understudied disaster phenomenon. Natural Hazards Review, 15(1), 1-12. http://dx.doi.org/10.1061/(ASCE)NH.1527-6996.0000113

Holguín-Veras, J., Jaller, M., Van Wassenhove, L. N., Pérez, N., \& Wachtendorf, T. (2012). On the unique features of post-disaster humanitarian logistics. Journal of Operations Management, 30(7), 494-506. http://dx.doi.org/10.1016/j.jom.2012.08.003

Holguín-Veras, J., Pérez, N., Jaller, M., Van Wassenhove, L. N., \& Aros-Vera, F. (2013). On the appropriate objective function for post-disaster humanitarian logistics models. Journal of Operations Management, 31(5), 262-280. http://dx.doi.org/10.1016/j.jom.2013.06.002

Joint Inspection Unit (2013), "Financing for Humanitarian Operations in the United Nations System", General Assembly. https://www.unjiu.org/en/reportsnotes/JIU\%20Products/JIU_REP_2012_11_English.pdf

Kelaher, D., \& Dollery, B. (2008). Cash and in-kind food aid transfers: The case of tsunami emergency aid in bandaaceh. International Review of Public Administration, 13(2), 117-128. http://dx.doi.org/10.1080/12294659.2008.10805125

Kovács, G., \& Spens, K. M. (2011). Trends and developments in humanitarian logistics-a gap analysis. International Journal of Physical Distribution \& Logistics Management, 41(1), 32-45. http://dx.doi.org/10.1108/09600031111101411

Lambert, D. M., Cooper, M. C., \& Pagh, J. D. (1998). Supply chain management: implementation issues and research opportunities. The international journal of logistics Management, 9(2), 1-20.

Maon, F., Lindgreen, A., \& Vanhamme, J. (2009). Developing supply chains in disaster relief operations through cross-sector socially oriented collaborations: A theoretical model. Supply 
A New Research Framework for Humanitarian Supply Chain Management

Chain Management: An International Journal, 14(2), 149-164. http://dx.doi.org/10.1108/13598540910942019

Mentzer, J. T., DeWitt, W., Keebler, J. S., Min, S., Nix, N. W., Smith, C. D., \& Zacharia, Z. G. (2001). Defining supply chain management. Journal of Business Logistics, 22(2), 1-25. http://dx.doi.org/10.1002/j.2158-1592.2001.tb00001.x

Monczka, T., \& Handfield (1998), "Purchasing and supply chain management", SouthWestern College Pub. (Cincinnati, Ohio), ISBN: 0538814950.

Natarajarathinam, M., Capar, I., \& Narayanan, A. (2009). Managing supply chains in times of crisis: A review of literature and insights. International Journal of Physical Distribution \& Logistics Management, 39(7), 535-573. http://dx.doi.org/10.1108/09600030910996251

Olsen, G. R., Carstensen, N., \& Høyen, K. (2003). Humanitarian crises: what determines the level of emergency assistance? Media coverage, donor interests and the aid business. Disasters, 27(2), 109-126.

Overstreet, R. E., Hall, D., Hanna, J. B., \& Rainer Jr, R. K. (2011). Research in humanitarian logistics. Journal of Humanitarian Logistics and Supply Chain Management, 1(2), 114-131. http://dx.doi.org/10.1108/20426741111158421

Özpolat, K.,Chen, Y., Hales, D., Yu, D., \& Yalcin, M.G. (2014). Using Contests to Provide Business Students Project-Based Learning in Humanitarian Logistics: PSAidExample.Decision Sciences Journal of Innovative Education, 12(4), 269-285.

Özpolat, K., Rilling, J., Altay, N., \& Chavez, E. (2015). Engaging Donors in Smart Compassion: USAID CIDI's Greatest Good Donation Calculator, Journal of Humanitarian Logistics and Supply Chain Management, 5(1),95-112.

Özpolat, K., Ribbink, D., Hales, D., \& Windle, R. (2015). Food Aid Procurement and Transportation Decision-making in Governmental Agencies: The United Nations/European Union versus the United States Approach, Transportation Journal, 54(2), 159-185.

Pontré, J., Welter, V., Malta, J. N. V., Faria, I., \& Chernyshova, A. (2011). Risk management in humanitarian procurement and supply chain. Journal of Public Procurement, 11(3).

Reisen, H. (2010). The multilateral donor non-system: Towards accountability and efficient role assignment. Economics: The Open-Access, Open-Assessment E-Journal, 4(2010-5), 1-22.

Rottkemper, B., Fischer, K., Blecken, A., \& Danne, C. (2011). Inventory relocation for overlapping disaster settings in humanitarian operations. OR Spectrum, 33(3), 721-749. http://dx.doi.org/10.1007/s00291-011-0260-5

Selvaretnam, G., Thampanishvong, K., \& Ulph, D. (2014). Saving and Re-building Lives: Determinants of Short-term and Long-term Disaster Relief. Eurasian Journal of Business and Economics, 7, 1-28.

Stromberg, D. (2007). Natural Disasters, Economic Eevelopment and Humanitarian Aid. Journal of Economic Perspectives, 21, 199-222.

Taskin, S., \&Lodree, E. (2011). A bayesian decision model with hurricane forecast updates for emergency supplies inventory management. Journal of the Operational Research Society, 62(6), 1098-1108. http://dx.doi.org/10.1057/jors.2010.14

Tatham, P. H., \& Pettit, S. J. (2010). Transforming humanitarian logistics: The journey to supply network management. International Journal of Physical Distribution \& Logistics Management, 40(8/9), 609-622. http://dx.doi.org/10.1108/09600031011079283 
Tatham, P., \& Kovács, G. (2010). The application of "swift trust" to humanitarian logistics. International Journal of Production Economics, 126(1), 35-45. http://dx.doi.org/10.1016/j.ijpe.2009.10.006

Thérien, J., \& Lloyd, C. (2000). Development assistance on the brink. Third World Quarterly, 21(1), 21-38. http://dx.doi.org/10.1080/01436590013206

Thomas, A., \&Mizushima, M. (2005). Logistics training: Necessity or luxury? Forced Migration Review, 22(22), 60-61. Tomaszewski, B., \& MacEachren, A. M. (2012). Geovisualanalytics to support crisis management: Information foraging for geo-historical context. Information Visualization, 11(4), 339-359. http://dx.doi.org/10.1177/1473871612456122

Van der Laan, Erwin A, De Brito, M. P., Van Fenema, P. C., \&Vermaesen, S. (2009). Managing information cycles for intra-organisational coordination of humanitarian logistics. International Journal of Services Technology and Management, 12(4), 362-390. http://dx.doi.org/10.1504/IJSTM.2009.025814

Van Wassenhove, L. N. (2006). Humanitarian aid logistics: Supply chain management in high geart. Journal of the Operational Research Society, 57(5), 475-489. http://dx.doi.org/10.1057/palgrave.jors.2602125

Van Wyk, E., Yadavalli, V., \& Bean, W. (2011). Strategic inventory management for disaster relief. Management Dynamics: Journal of the Southern African Institute for Management Scientists, 20(1), 32-41.

\section{APPENDIX A - Article Count By Journal in Alphabetical Order}

\begin{tabular}{|lc|}
\hline Journal & Paper \# \\
\hline Administrative Science Quarterly & 1 \\
Advances in Applied Probability & 1 \\
Air Quality, Atmosphere, \& Health & 1 \\
American Journal of Public Health & 3 \\
American Review of Public Administration & 1 \\
Annals of Operations Research & 3 \\
Applied Economics & 1 \\
Asian Journal of Women's Studies & 4 \\
Benchmarking & 1 \\
Business Horizons & 1 \\
Canadian Social Science & 1 \\
Computers and Industrial Engineering & 2 \\
Computers and Operations Research & 5 \\
Conflict \& Health & 2 \\
Corporate Communications & 1 \\
Corporate Reputation Review & 1 \\
Decision Support Systems & 1 \\
Defense \& Security Analysis & 1 \\
Demography & 1 \\
Disaster Prevention and Management & 1 \\
Disasters & 16 \\
Economics & 6 \\
Economics Letters & 1 \\
Engineering Simulation & 1 \\
Environment Systems \& Decisions & 1 \\
Environmental Management & 3 \\
Environmental Modeling \& Assessment & 1 \\
Ethics and Information Technology & 1 \\
\hline
\end{tabular}


A New Research Framework for Humanitarian Supply Chain Management

\begin{tabular}{|c|c|}
\hline Journal & Paper \# \\
\hline Eurasian Journal of Business and Economics & 1 \\
\hline European Journal of Operational Research & 18 \\
\hline Expert Systems with Applications & 1 \\
\hline Foundations and Trends in Technology Information and Operations Management & 1 \\
\hline Fuzzy Sets and Systems & 2 \\
\hline IEEE Transactions on Professional Communication & 1 \\
\hline IIE Solutions & 1 \\
\hline Industrial Management + Data Systems & 1 \\
\hline Information \& Management & 1 \\
\hline Information Systems and eBusiness Management & 1 \\
\hline Information Systems Frontiers & 3 \\
\hline Information Technologies \& International Development & 1 \\
\hline Information Technology \& People & 1 \\
\hline Information Visualization & 1 \\
\hline Interdisciplinary Journal of Contemporary Research In Business & 2 \\
\hline Interfaces & 3 \\
\hline International Journal of Academic Research & 1 \\
\hline International Journal of Business and Social Science & 1 \\
\hline International Journal of Computational Intelligence Systems & 1 \\
\hline International Journal of Disaster Resilience in the Built Environment & 2 \\
\hline International Journal of Government Auditing & 1 \\
\hline International Journal of Innovation, Management and Technology & 1 \\
\hline International Journal of Logistics & 1 \\
\hline International Journal of Logistics Management & 1 \\
\hline International Journal of Operations \& Production Management & 1 \\
\hline International Journal of Organizational Analysis & 1 \\
\hline International Journal of Physical Distribution \& Logistics Management & 17 \\
\hline International Journal of Production Economics & 8 \\
\hline International Journal of Production Research & 1 \\
\hline International Journal of Productivity and Performance Management & 1 \\
\hline International Journal of Risk Assessment and Management & 1 \\
\hline International Journal of Services Technology and Management & 3 \\
\hline International Review of Public Administration & 1 \\
\hline International Transactions in Operational Research & 2 \\
\hline Journal of Advanced Transportation & 1 \\
\hline Journal of Advances in Management Research & 1 \\
\hline Journal of Applied Probability & 3 \\
\hline Journal of Business Logistics & 2 \\
\hline Journal of Contingencies \& Crisis Management & 1 \\
\hline Journal of Contingencies and Crisis Management & 2 \\
\hline Journal of Economic Perspectives & 1 \\
\hline Journal of Geographic Information System & 1 \\
\hline Journal of Global Optimization & 1 \\
\hline Journal of Humanitarian Logistics and Supply Chain Management & 33 \\
\hline Journal of Industrial and Management Optimization & 1 \\
\hline Journal of Industrial Engineering and Management & 1 \\
\hline Journal of Information Technology Theory and Application & 1 \\
\hline Journal of Infrastructure Systems & 2 \\
\hline Journal of International Peace Operations & 1 \\
\hline Journal of Japan Industrial Management Association & 1 \\
\hline Journal of Management and Organization & 1 \\
\hline
\end{tabular}




\begin{tabular}{|c|c|}
\hline Journal & Paper \# \\
\hline Journal of Manufacturing Technology Management & 1 \\
\hline Journal of Multi-criteria Decision Analysis & 2 \\
\hline Journal of Operations Management & 4 \\
\hline Journal of Public Procurement & 2 \\
\hline Journal of Risk and Insurance & 1 \\
\hline Journal of Supply Chain Management & 2 \\
\hline Journal of Sustainable Development & 1 \\
\hline Journal of the Association for Information Systems & 1 \\
\hline Journal of the Operational Research Society & 5 \\
\hline Journal of the Royal Statistical Society Series C -- Applied Statistics & 1 \\
\hline Knowledge-Based Systems & 1 \\
\hline Management Dynamics & 1 \\
\hline Management Science & 2 \\
\hline Mathematical and Computer Modelling & 1 \\
\hline Natural Hazards Review & 3 \\
\hline Naval Research Logistics & 2 \\
\hline Naval War College Review & 1 \\
\hline Networks and Spatial Economics & 1 \\
\hline Nonlinear Analysis: Real World Applications & 1 \\
\hline Operations Management Research & 2 \\
\hline Operations Research & 1 \\
\hline Operations Research Letters & 2 \\
\hline Optimization Letters & 1 \\
\hline OR Insight & 1 \\
\hline OR Spectrum & 9 \\
\hline Production and Operations Management & 2 \\
\hline Public Administration \& Development & 1 \\
\hline Rairo-Operations Research & 1 \\
\hline Records Management Journal & 1 \\
\hline Review of African Political Economy & 1 \\
\hline Risk & 1 \\
\hline Risk Analysis & 5 \\
\hline Safety Science & 5 \\
\hline Socio-Economic Planning Sciences & 6 \\
\hline Structural Safety & 1 \\
\hline Supply Chain Management & 2 \\
\hline The European Journal of Development Research & 1 \\
\hline The International Journal of Public Sector Management & 1 \\
\hline The Journal of the Operational Research Society & 3 \\
\hline Transportation Journal & 1 \\
\hline Transportation Research & 6 \\
\hline Transportation Research Part A & 1 \\
\hline Transportation Research Part A -- Policy and Practice & 1 \\
\hline Transportation Research Part B -- Methodological & 1 \\
\hline Transportation Research Record & 1 \\
\hline Transportation Science & 1 \\
\hline Total & 293 \\
\hline
\end{tabular}

